\title{
ARL Library Liaison Institute What we learned about needs and opportunities for reskilling
}

I n June 2015, the University of Toronto, Cornell University, and Columbia University partnered with the Association of Research Libraries (ARL) on a library liaison institute to bring together a group of 50 liaison librarians. The goal of the institute was to explore the future of liaison work and discuss how to measure its impact. The ARL Library Liaison Institute, held at Cornell University, was a day-and-a-half program to facilitate conversations and group exercises. At the Institute we collected information about what liaisons value in their work, and how they see their jobs changing as a result of new research practices. The data shed light on liaisons' anxiety about perceived skill gaps in view of new expectations. ARL released a full report of the Institute in December $2015 .^{1}$

This column will focus on some of the needs for training and reskilling that both participants and organizers identified during the Institute, drawing attention to the increasing need to support scholarly communication and liaisons' level of engagement with this topic.

\section{Scenarios}

The first exercise of the Institute asked liaisons to focus on the future of their work by imagining several scenarios. (A full description of these scenarios is available in the report on the Institute.) This exercise yielded a lot of information about "reskilling" because we asked the participants to think about what preparation will be required for these potential futures, and what will be needed from library management to make these future scenarios plausible. Liaisons worked in groups to discuss the scenarios and answer these questions. Several major themes emerged from these discussions.

\section{Project management}

Project management first surfaced as a theme during the scenario session, but it also came up throughout the Institute as an important skill and role for liaisons in the future. Liaisons cited a need for training in this area for managing their own work and the assignments stemming from partnerships with faculty and students for research projects. One liaison suggested that a project management approach has the potential to change the committee culture in libraries.

Nisa Bakkalbasi is assessment coordinator at Columbia University Libraries, email: nisa.bakkalbasi@ columbia.edu, Barbara Rockenbach is director of Humanities and History Libraries at Columiba University Libraries, email: brockenback@columbia. edu, Kornelia Tancheva is associate university librarian for research and learning services at Cornell University Library, email: kt18@cornell.edu, and Rita Vine is head of faculty and student engagement at the University of Toronto, email: rita.vine@utoronto.ca

Contact series editors Adrian Ho, director of digital scholarship at the University of Kentucky Libraries, and Patricia Hswe, digital content strategist at Penn State University, at crlnscholcomm@gmail.com with article ideas

๑ 2016 Nisa Bakkalbasi, Barbara Rockenbach, Kornelia Tancheva, and Rita Vine 
Instead of committees, task forces would be set up with specific goals and deliverables with deadlines.

\section{Skill and attitude changes}

In each scenario, the groups noted that attitudes toward liaison work need to change on the part of the liaisons themselves. Phrases such as "mind-set change," being more "nimble" or "flexible," and a need to be "more comfortable with and capable of outreach" were cited as requirements in the possible futures described in the scenarios. This theme was coupled with numerous calls for training and professional development to gain the necessary skills to engage with students, faculty, and researchers in new ways. One participant described liaisons as "stem cell librarians," meaning that they need to grow into whatever is needed in response to changing user needs.

\section{Empathy}

Following closely on the notion of attitude changes, came an appeal for empathy as being central to the liaison role. This emerged as a theme when several liaisons spoke about the danger of making assumptions about what our users want from the library. There is much value in learning about what faculty and students are struggling with and thinking creatively about how the library can address their "pain points." Crucial to empathy is learning to listen to our users and being able to place ourselves in their shoes.

Major questions about traditional roles, skills, and expertise arose during the conversations about reskilling. The desire for acquiring new skills was often accompanied by anxiety about what that means for well-established elements in many liaisons' portfolios.

\section{Reference and one-shot instruction}

Many liaisons at the Institute were hesitant to give up in-person reference or one-shot instruction. One liaison suggested that we reframe how we talk about instruction, because "one-shot" neglects the potential for relationship development with faculty surrounding teaching and learning activities. If a relationship has been established, the one-shot should be one interaction among many. Another liaison described the reference interview as the primary point of intellectual discourse in a liaison's job. These sentiments revealed some liaisons' adherence to the traditional roles of librarians. However, other participants perceived reference as a legacy service and suggested rethinking the need to hold on to it.

Other liaisons saw an opportunity to reinvent reference and one-shot instruction through training students or other library staff to do this work. One liaison stated that students can be great ambassadors for the library and their involvement in peer-to-peer teaching can improve student learning in a more holistic way by better connecting research resources to the course material.

\section{Expertise}

The notion of expertise was a theme that engendered the most discussion and divergence among the liaisons. Many participants felt that expertise is at the core of what it means to be a liaison. Most defined it as subject expertise, but there were a few liaisons with functional roles (data management, digital humanities, GIS) who saw expertise in the realm of functional specialties. Liaisons argued vehemently that this expertise is what constitutes their credibility with faculty and that some liaisons' compensation and faculty status are based on expertise. Some felt subject expertise enables liaisons to be conversant with faculty in the disciplines they support as well as to understand the research methodologies of those disciplines.

On the other hand, some liaisons felt that subject expertise is not an effective way to define liaisons. One participant stated that the subject liaison model is not scalable at larger institutions with many disciplines, centers, and institutes. Another felt that even with a doctoral degree, a liaison cannot have an in-depth understanding of a discipline at a level that faculty do in their 
own subject areas. Therefore, we need to be careful about setting up expectations about depth of knowledge when marketing subject expertise.

Several liaisons argued that faculty increasingly come to librarians for expertise in areas such as student support needs and scholarly communication. With respect to the latter, the participants noticed that copyright and publishing issues are "pain points" mostly for early- and mid-career faculty. They also realized that their jobs need to incorporate expert support for copyright, institutional repository, funder mandates, and open access publishing in individual disciplines.

After a healthy debate, we discussed whether expertise is an individual or collective attribute. Due to the increase in multidisciplinary work and new specializations, the notion of team-based expertise resonated with many of the liaisons.

We also discussed the merits of teambased expertise (working in teams) versus network-based expertise (referring users to others in an organization). Although the participants thought both approaches are workable, they acknowledged that referral will always be necessary for certain topics.

For example, on scholarly communication services, liaisons can work in a team to promote the use of institutional and subject repositories. However, they may refer author rights support to a copyright librarian.

\section{Personal reflections}

As part of a "Personal Reflections" activity at the end of the event, liaisons explicitly addressed training and reskilling, answering a question about what they need from administrators to be equipped for the future. Specifically on the theme of reskilling, the liaisons were asked three questions:

1. What excites/motivates you the most?

2. What scares you the most?

3. How can library administration support you?
The following is a summary of the basic concepts and sentiments that the liaisons expressed in response to the questions.

A review of the responses to the first question (What excites/motivates you the most?) tells us that while individual liaisons differ in what specifically excited or motivated them, there are three common fundamental motivators: professional rejuvenation, collaboration, and administrative vision and support.

The majority of the participants expressed excitement about applying the new skills and concepts discussed at the Institute to practices and in one's library, especially by taking a more user-centered approach. Set in a retreat-like atmosphere, the Institute clearly provided professional rejuvenation for many of the liaisons. The participants expressed excitement about sharing ideas and best practices with colleagues from different institutions, and thinking about prospects for more collaboration in the future. About one-third of the participants stated they were inspired by the support they received from their respective library administrators, and were motivated by the goals and priorities proposed by them.

With reference to the second question (What scares you the most?), four major themes of concern emerged from the responses: abandonment of core duties, miscommunication, work overload, and reluctance to change. The liaisons expressed concern about new librarianship models aimed at cutting back, or eliminating, core duties such as reference, instruction, and subject specialization. The perception is that these core duties were created through a long history of determining student and faculty needs. Some liaisons felt anxious that libraries may be relinquishing their traditional role in helping users to pursue new priorities that are less well-defined.

Participants expressed concern about the possibility that library administrators and librarians will add new priorities without shedding existing responsibilities, with the consequence that no priorities will be ac- 
complished well and librarians will face an unmanageable workload.

Among other concerns was miscommunication or misunderstanding about the potential roles liaisons could play in their key constituents' research lifecycles. Also, rapid changes in research practices and scholarly communication create significant challenges for scholars and give rise to new needs from users and the university environment. There was concern from the participants about their peers' reluctance to change and adapt to these new needs.

In response to the last question (How can library administration support you?), the pervasive themes were advocacy, feedback, training, and managing workload. The liaisons stated that library administration plays an important role of advocacy in promoting libraries' needs and capabilities to university administrators, faculty, students, and across and outside their institutions. An open dialogue among library units, library administration, faculty, students, and peer institutions will be important in determining needs, priorities, and sustainability of new initiatives. Librarians will need training for new skills and professional development. In order to manage workload, it is important that the library administration provide realistic guidelines about how new priorities replace existing duties.

\section{Conclusion}

The Institute participants' input highlighted some potential training areas that move the focus of liaison work from what we do (reference, instruction, and collection development) to the impact we make. Many of the training and reskilling needs uncovered at the Institute show the necessity to take a broader view of liaisons' work and the context in which they do it.

Looking beyond the library to the larger institutional context, liaisons can better understand the impact of their work by aligning the work they do with the larger challenges the institution is tackling. While scholarly communication issues surfaced at

\section{With reference to the second ques- tion (What scares you the most?), four major themes of concern emerged from the responses: aban- donment of core duties, miscommu- nication, work overload, and reluc- tance to change.}

the Institute, they did not rise to the top of the list for most liaisons. We have identified this as a possible area of disconnect between institutional goals and individual liaison goals.

Success occurs when the library is a part of collective problem solving at the university level. For instance, it is apparent that many institutions are grappling with issues of scholarly communication. If liaisons engage in addressing such issues, they will likely be viewed as contributing to collective problem solving at their institution.

In the coming months, the Institute organizers will use the collected data to focus on training and reskilling needs. In addition, we plan to develop a set of metrics to measure liaison impact in existing service areas and identify gaps in a rapidly changing research and scholarly communication environment.

The Institute enabled us to capture a baseline of where we are today with liaison work and to spur some creative thinking about where we might go. Metrics to measure liaison impact will empower us to evaluate faculty and student needs iteratively, and continue to evolve our skills to meet these needs.

\section{Note}

1. The Association of Research Libraries /Columbia University/Cornell University /University of Toronto Pilot Library Liaison Institute Final Report can be found at www.arl. org/storage/documents/publications/library -liaison-institute-final-report-dec2015. pdf. $n$ 